\title{
Orthotropic Material and Anisotropic Damage Mechanics Approach for Numerically Seismic Assessment of Arch Dam-Reservoir-Foundation System
}

\author{
M. A. Hariri-Ardebili, ${ }^{\mathrm{a}, 1}$ and H. Mirzabozorg ${ }^{\mathrm{b}, 2}$ \\ ${ }^{a}$ University of Colorado, Boulder, USA \\ ${ }^{b}$ K. N. Toosi University of Technology, Tehran, Iran \\ ${ }^{1}$ mohammad.haririardebili@colorado.edu \\ 2 mirzabozorg@kntu.ac.ir
}

УДК 539.4

\section{Ортотропный материал и анизотропный подход в рамках механики повреждения к численной оценке сейсмической реакции системы плотина-резервуар-основание}

\author{
М. А. Харири-Ардебили', Х. Мирзабозорг \\ а Колорадский университет, Боулдер, США \\ б Технологический университет имени К. Н. Туси, Тегеран, Иран \\ В отличие от моделирования усадочных ивов, при численном анализе бетонных арочных \\ плотин работа и влияние строительных швов обычно не учитываются. Исследуется сейсми- \\ ческая нелинейная реакиия системы (бетонная) арочная плотина-резервуар-основание с \\ учетом действия строительных швов на основе ортотропного материала. Представленный \\ анизотропный подход к механике повреждения изменен для учета слабых горизонтальных \\ плоскостей между слоями бетона в процессе строительства. Эта модель допускает учет \\ характеристики предварительного размягчения, критерия возникновения размягчения и ха- \\ рактеристики анизотропного растрескивания. С помощьюю метода ступенчатых переме- \\ щений, предполагая, что скальное основание состоит из невесомых жестких тел, решена \\ система связанных уравнений движения в системе плотина-резервуар. Движение грунта по \\ трехкомпонентной технологии возбуждает данную систему на максимально вероятном \\ уровне. Обнаружено, что использование ортотропного материала увеличивает смещение \\ гребня плотины и, как следствие, повреждение тела плотины в большей степени по сравне- \\ нию с использованием распространенного изотропного материала.
}

Ключевые слова: анизотропное повреждение, ортотропный материал, взаимодействие в системе поток-конструкция, арочная плотина, оценка сейсмической реакции.

Introduction. Performance of concrete dams can be affected by various phenomena in which one of the most important factors is earthquake shaking. Various types of concrete dams show different failure modes under seismic loads. Concrete arch dams are built as partially independent block where shear keys and grouting the contraction joints leads to monolithic behavior of the structure. 
However the contraction joints are assumed to have very little tensile strength under seismic loading and blocks can have opening and sliding with respect to the adjacent ones. The important point which is usually neglected in seismic safety evaluation of conventional and RCC arch dams is effects of weak planes between concrete lifts formed during construction phase.

A lift joint is the horizontal joint between the old and fresh concrete pouring layer, which its thickness varies between 2 to $3 \mathrm{~m}$ depending on the rate of concrete pouring during a day. Lift joint is a key factor in successful construction and operation of RCC arch dams because the quality of the bond between successive layers of concrete determines the overall strength and seepage condition of the dam. At lift joints, the coarse aggregate becomes segregated, and thus forms a discontinuity from one lift to another through which water can flow. The condition of the lower surface, time delay between placement of lifts, compaction and consistency of the covering concrete are factors affecting the strength of lift joints. Although all the necessary arrangements are considered for implementing the lift joints in best condition, the strength of this part of the dam is less than the intact concrete.

There is very little literature considering effect of lift joints on seismic behavior of conventional and RCC arch dams. Hess [1] studied RCC lift joints strength under various conditions as well as seismic loading. Arabshahi and Lotfi [2] investigated the effects of contraction, peripheral and lift joints on seismic response of arch dams. They used zero thickness interface element for modeling the joints. Fronteddu et al. [3] studied static and dynamic behavior of concrete lift joint interfaces experimentally. Puntel et al. [4] investigated the cyclic behavior of concrete dam joints considering both experimental and numerical aspects. Mojtahedi and Fenves [5] considered the effects of contraction and lift joints of the Pacoima dam in 1994 Northridge earthquake based on uniform and non-uniform free-field ground motions. Malla and Wieland [6,7] studied the 3D behavior of an arch-gravity dam due to earthquake loading and AAR effects considering the horizontal crack generated first on the downstream (DS) face near the gallery utilizing the discrete crack approach.

In the field of damage mechanics, many researchers have proposed damagebased models for simulating the behavior of brittle materials as well as mass concrete. Hansen and Schreyer [8], Doghri and Tinel [9], Menzel et al. [10], Voyiadjis et al. [11] used continuum damage mechanics approach for description of material behavior under various loading conditions. Isotropic damage mechanics approach using one or two damage variables have been studied by researchers such as Lee and Fenves [12], Jason et al. [13], Bonora et al. [14], Jason et al. [15], Pirondi et al. [16], Wu et al. [17], Celentano and Chaboche [18]. Anisotropic damage mechanics approach have been studied by Chaboche [19], Voyiadjis and Abu-Lebdeh [20], Govindjee et al. [21], Halm and Dragon [22], Carol et al. [23], Hansen et al. [24], Gatuingt and Pijaudier-Cabot [25], Brunig [26], Cicekli et al. [27], Hammi and Horstemeyer [28].

On the other hand, some researchers used the methods based on damage mechanics and combination of this method with theory of plasticity, discrete crack approach and other techniques in order to simulation of crack and failure in concrete dams. Ghrib and Tinawi [29, 30] and Mirzabozorg et al. [31] used damage 
mechanics approach to study the static and dynamic behavior of concrete gravity dams. Gunn [32, 33] used the damage mechanics approach in 3D space for analyzing concrete structures under the static loads. Horii and Chen [34] illustrated various methods to model the nonlinear behavior of mass concrete in gravity dams. In their study, the problems in crack modeling; computational algorithm and damping implementation were discussed in conjunction with safety assessment of concrete dam against large earthquakes. Oliver et al. [35] presented a continuum strong discontinuity approach to consider cracking of concrete. Criteria for onset and propagation of material failure and specific finite elements with embedded discontinuities were sketched and some numerical simulations of cracking in plain and reinforced concrete specimens were presented. Pekau and Yuzhu [36] presented a study on the dynamic behavior of the fractured Koyna dam during earthquakes using the distinct element method. They modeled the hydrodynamic effect using the added mass approach. Calayir and Karaton [37] presented a paper in which the earthquake damage response of concrete gravity dams is considered including the effect of reservoir interaction. In their work, 2D damage mechanics approach similar to that introduced in Mirzabozorg et al. [31] was utilized to model the nonlinear behavior of the dam body in 2D space and the reservoir was modeled in the Lagrangian space. Ardakanian et al. [38] developed an anisotropic damage mechanics approach to consider the nonlinear seismic response of concrete dams in $3 \mathrm{D}$ space when the reservoir is assumed compressible. Oliveira and Faria [39] studied the failure scenarios of concrete dams. In their work, a continuum damage mechanics model that incorporates two independent scalar damage variables in tension and compression was adopted in which both in tension and compression material softening is reproduced.

In the present study, the nonlinear response of an arch dam-reservoir system is investigated under seismic loading. An anisotropic non-uniform damage mechanics approach was used for cracking simulation of mass concrete under dynamic loads considering fluid-structure interaction effects. Non-uniform cracking means that cracks in the candidate element propagate within the Gaussian points.

The major efficiency of this method is the ability of evaluating nonlinear seismic behavior of concrete dams in $3 \mathrm{D}$ space using large elements and also, its ability of more accurate tracing crack paths within the dam body and reducing time and saving analysis requirements. Considering that all previous investigations on arch and arch RCC dams are just take into account the effects of contraction and in some cases perimetral joints effects and also almost all of them used the discrete crack approach for simulation of weak vertical planes, in the present paper the effects of horizontal lines (lift joints) are simulated based on continuum mechanics approach and assuming orthotropic characteristics for mass concrete in the direction perpendicular to the lift surfaces.

1. Constitutive Relationship for Mass Concrete. In order to analysis of a structural system utilizing the damage mechanics approach, the proposed method should be able to simulate the behavior of the element in different states as follow; Pre-softening behavior, fracture energy conservation, nonlinear behavior during the softening phase and finally crack closing/reopening behavior. The following sub-sections represent a brief review on general concepts of the utilized method in this study. 
1.1. Pre-Softening Relationship. In the general, the relationship of the stress and strain vectors at the pre-softening phase is given as

$$
\{\sigma\}=[D]_{0}\{\varepsilon\}
$$

where $[D]_{0}$ is the elastic modulus matrix and $\{\sigma\}$ and $\{\varepsilon\}$ are the vector of stress and strain components, respectively. Assuming isotropic linear behavior at the pre-softening phase, the modulus matrix of $[D]_{0}^{\text {isotropic }}$ is given as

$$
[D]_{0}^{\text {isotropic }}=\frac{E}{(1+v)(1-2 v)}\left[\begin{array}{ccccccc}
1-v & & & & \\
\text { sym. } & \\
v & 1-v & & & \\
v & v & 1-v & & \\
0 & 0 & 0 & \frac{1-2 v}{2} & & \\
0 & 0 & 0 & 0 & \frac{1-2)}{2} & \\
0 & 0 & 0 & 0 & 0 & \frac{1-2)}{2}
\end{array}\right] \text {, }
$$

where $E$ and $v$ are isotropic modulus of elasticity and Poisson's ratio within material. Similarly orthotropic elastic modulus matrix $[D]_{0}^{\text {orthotropic }}$ may be used for simulating the linear behavior of materials such as RCC as following:

$$
[D]_{0}^{\text {orthotropic }}=
$$

$$
=\left[\begin{array}{cccccc}
\frac{1-v_{y z} v_{z y}}{E_{y} E_{z} \Delta} & & & & & \\
\frac{v_{x y}+v_{x z} v_{z y}}{E_{z} E_{x} \Delta} & \frac{1-v_{z x} v_{x z}}{E_{z} E_{x} \Delta} & & & & \\
\frac{v_{x z}+v_{x y} v_{y z}}{E_{x} E_{y} \Delta} & \frac{v_{y z}+v_{x z} v_{y z}}{E_{x} E_{y} \Delta} & \frac{1-v_{x y} v_{y x}}{E_{x} E_{y} \Delta} & & & \\
0 & 0 & 0 & 2 G_{y z} & & \\
0 & 0 & 0 & 0 & 2 G_{z x} & \\
0 & 0 & 0 & 0 & 0 & 2 G_{x y}
\end{array}\right],
$$

in which,

$$
\Delta=\frac{1-v_{x y} v_{y x}-v_{y z} v_{z y}-v_{z x} v_{x z}-2 v_{x y} v_{y z} v_{z x}}{E_{x} E_{y} E_{z}}
$$

where $v_{x y}, v_{y x}, v_{x z}, v_{z x}, v_{y z}$, and $v_{z y}$ are Poisson's ratio respect to $x, y$, and $z$ axis, $E_{x}, E_{y}$, and $E_{z}$ are the Young modulus, and $G_{x y}, G_{y z}$, and $G_{z x}$ are shear modulus in planes parallel to $x y, y z$, and $z x$ planes, respectively. 
The above mentioned matrix is a symmetric and so we have

$$
\frac{v_{y z}}{E_{y}}=\frac{v_{z y}}{E_{z}}, \quad \frac{v_{z x}}{E_{z}}=\frac{v_{x z}}{E_{x}}, \quad \frac{v_{x y}}{E_{x}}=\frac{v_{y x}}{E_{y}} .
$$

In addition, the shear modulus can be obtained as follow:

$$
G_{i j}=\frac{E_{j}}{2\left(1+v_{i j}\right)},
$$

where $i, j=x, y, z$ are three orthogonal directions.

1.2. Softening Initiation Criterion. In the present model, the uniaxial strain energy (the area under the stress-strain curve up to the peak stress point or apparent tensile stress) is used as softening initiation criterion. The crack initiates when uniaxial strain energy density, $\sigma_{1} \varepsilon_{1} / 2$, is greater than $U_{0}$ in static conditions

$$
U_{0}=\int_{0}^{\varepsilon_{i}} \sigma d_{\varepsilon}=\frac{\sigma_{i} \varepsilon_{i}}{2}
$$

where $\sigma_{i}$ and $\varepsilon_{i}$ are the apparent tensile strength and its corresponding strain, respectively. Considering that the properties of material changes under dynamic loads, the strain rate effect under dynamic loads is applied on the crack initiation criterion as follow:

$$
U_{0}^{\prime}=\frac{\sigma_{i}^{\prime 2}}{E}=U_{0}\left(D M F_{e}\right)^{2},
$$

where $D M F_{e}$ is dynamic magnification factor and the parameters with the prime sign indicate properties in dynamic condition.

1.3. Softening Relationship. During the softening phase the elastic stressstrain relationship is replaced using the damaged modulus matrix in each of the three principal directions. In the present paper, the secant modulus stiffness (SMS) approach is used for the stiffness matrix formulation. Based on this approach, the constitutive law is defined in terms of total stresses and strains as shown in Fig. 1.

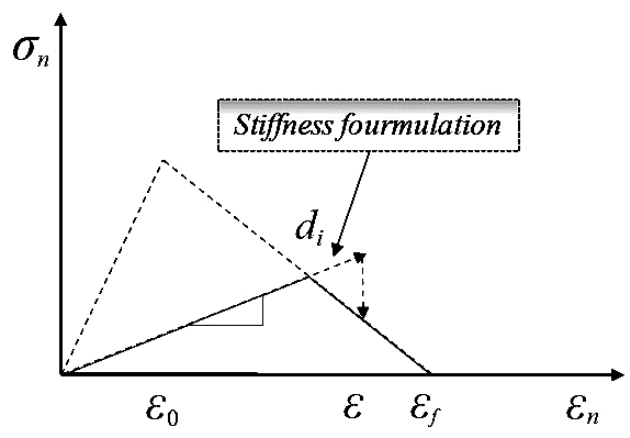

Fig. 1. SMS formulation of the modulus matrix. 
Considering the energy equivalence principle and neglecting the coupling between the three principal fracture modes, the damaged modulus matrix is given as

$$
[D]_{d}=\left[\begin{array}{cc}
{[D]_{d}^{t}} & 0 \\
0 & {[D]_{d}^{r}}
\end{array}\right]
$$

where

$$
\begin{aligned}
& {[D]_{d}^{t}=\frac{E}{(1+v)(1-2 v)} \times} \\
& \times\left[\begin{array}{ccc}
(1-v)\left(1-d_{1}\right)^{2} & \text { sym. } \\
v\left(1-d_{1}\right)\left(1-d_{2}\right) & (1-v)\left(1-d_{2}\right)^{2} & \\
v\left(1-d_{1}\right)\left(1-d_{3}\right) & v\left(1-d_{2}\right)\left(1-d_{3}\right) & (1-v)\left(1-d_{3}\right)^{2}
\end{array}\right] \\
& {[D]_{d}^{r}=G\left[\begin{array}{ccc}
\frac{2\left(1-d_{1}\right)^{2}\left(1-d_{2}\right)^{2}}{\left(1-d_{1}\right)^{2}+\left(1-d_{2}\right)^{2}} & & \text { sym. } \\
0 & \frac{2\left(1-d_{2}\right)^{2}\left(1-d_{3}\right)^{2}}{\left(1-d_{2}\right)^{2}+\left(1-d_{3}\right)^{2}} & \\
0 & 0 & \frac{2\left(1-d_{1}\right)^{2}\left(1-d_{3}\right)^{2}}{\left(1-d_{1}\right)^{2}+\left(1-d_{3}\right)^{2}}
\end{array}\right] \text {, }}
\end{aligned}
$$

where $d_{1}, d_{2}$, and $d_{3}$ are the damage variables corresponding to the principal strains in the local directions. Satisfying the principle of energy equivalence and assuming the linear stress-strain curve in the post-peak phase as shown in Fig. 1, $d_{i}$ is given as

$$
d_{i}=1-\sqrt{\frac{\varepsilon_{0}}{\varepsilon_{i}}\left(1-\left(\frac{\varepsilon_{i}-\varepsilon_{0}}{\varepsilon_{f}-\varepsilon_{0}}\right)\right)},
$$

where $\varepsilon_{0}$ and $\varepsilon_{f}$ are the stains corresponding to the crack initiation and no resistance strain, respectively, and $\varepsilon_{i}$ is the principal strain of the element in the considered direction. The proposed modulus matrix includes all of the principal fracture modes. However, as mentioned, in the proposed formulation, the interaction between the three principal fracture modes and mixed modes is neglected.

The damaged modulus matrix shown in equation (9) is in the local coordinate which is corresponding to the direction of the principal strains. This matrix should be transformed to the global coordinate as following:

$$
[D]_{S}=[T]^{T}[D]_{d}[T]
$$

where $[T]$ is the strain transformation matrix. Based on the maximum strain reached in each principal direction, the secant modulus matrix is determined as 
shown in Fig. 1. Clearly, increasing of the strain leads to increasing the corresponding damage variable and finally, when the strain reaches to the fracture strain, the element is fully cracked in the corresponding direction and the related damage variable sets to be unit. In fact, any change in the principal strain or its direction leads to update requirement of the global constitutive matrix, $[D]_{S}$. Satisfying the fracture energy conservation principle in the static and the dynamic loading conditions, the no resistance strain is given as

$$
\varepsilon_{f}=\frac{2 G_{f}}{\sigma_{0} h_{c}}, \quad \varepsilon_{f}^{\prime}=\frac{2 G_{f}^{\prime}}{\sigma_{0}^{\prime} h_{c}},
$$

where $h_{c}$ is the characteristic dimension of the cracked Gaussian point and is assumed equal to the third root of the Gaussian point's contribution volume within the cracked element. The primed quantities show the dynamic constitutive parameters. The strain-rate sensitivity of the specific fracture energy is taken into account through the dynamic magnification factor $D M F_{f}$ as follows:

$$
G_{f}^{\prime}=G_{f} D M F_{f}
$$

It is worth noting that $D M F_{f}$ is mainly contributed by $D M F_{e}$.

1.4. Crack Closing/Reopening. In the current formulation, co-axial rotating crack model (CRCM) is used to simulation of the cracked Gaussian point's behavior within the cracked elements. In this approach shear stiffness factors [arrays of matrix in Eq. (11)] are determined based on the state of the Gaussian point in each principal direction in the current time step. As softening within the considered element progresses, the shear stiffness factor in the cracked Gaussian point decreases corresponding to the state of the principle strains and may reach to zero value and therefore, the constitutive matrices contributions of the cracked Gaussian point and finally, the constitutive matrix of the considered element must be updated as these factors are changed [40, 41].

Under the cyclic loading, there is residual strain in the closed Gaussian point. This concept has been used in the element level approaches in which the total strain in each Gaussian point is decomposed into the two components of the elastic and the residual strain given as Ardakanian et al. [38]:

$$
\varepsilon=\varepsilon^{e}+\varepsilon^{i n}=\varepsilon^{e}+\lambda \varepsilon_{\max }
$$

where $\varepsilon_{\max }$ is the maximum principal strain which the Gaussian point has reached during the previous cycles and $\lambda$ is the ratio between the residual strain in the closed Gaussian point and the maximum principal strain and is normally given as 0.2 . Figure 2 summarizes the crack closing/reopening algorithm applied in the present numerical approach.

2. Dam-Reservoir Interaction. In order to obtain accurate responses of dam under dynamic loads it is required that an appropriate formulation is governed for dam-reservoir interaction problem and suitable boundary conditions are defined for reservoir medium. 


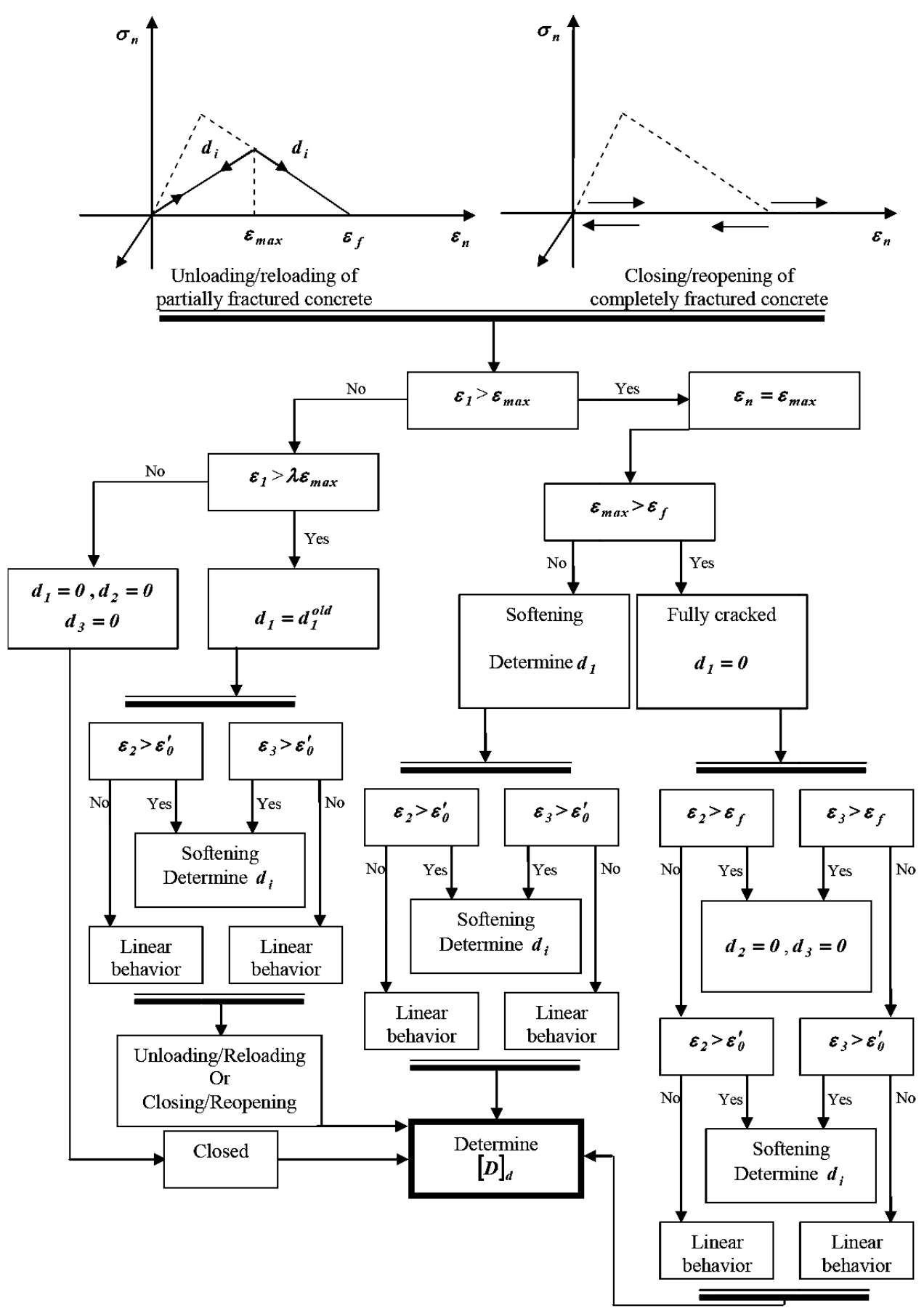

Fig. 2. The closing/reopening algorithm for cracked Gaussian point [40].

2.1. Boundary Conditions. Hydrodynamic pressure distribution in reservoir is governed by pressure wave equation. Assuming that water is linearly compressible and neglecting viscosity, small-amplitude irrotational motion of water is governed by Helmholtz equation given as 


$$
\nabla^{2} p(x, y, z)=\frac{1}{C^{2}} \ddot{p}(x, y, z, t),
$$

where $p$ is hydrodynamic pressure and $C$ is velocity of pressure wave in water. The boundary conditions required for solving the above differential equation is given in Fig. 3. In addition, this figure represents the coupled equations governing the dynamic behavior of the structure and the reservoir stored in its upstream (US).

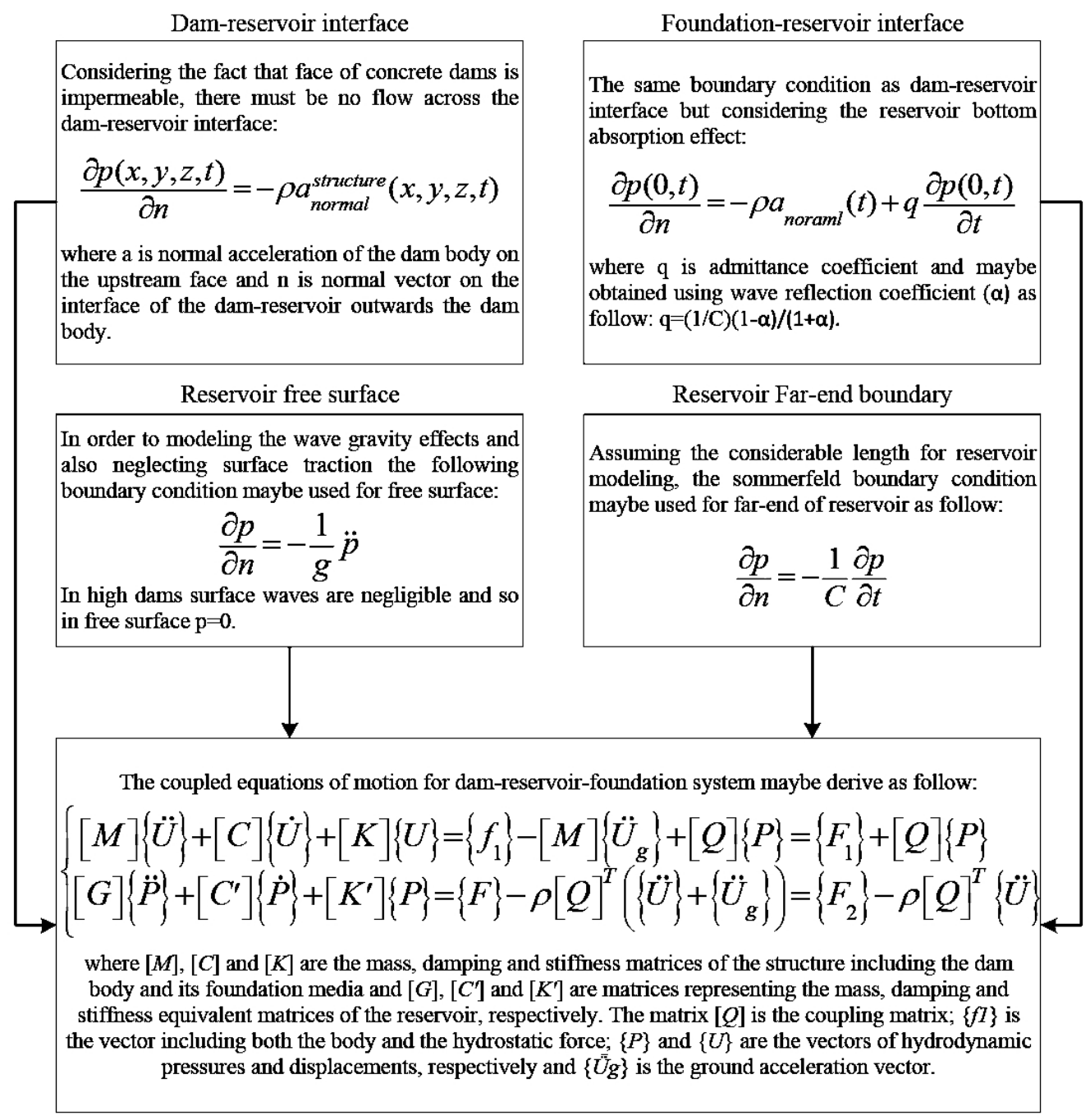

Fig. 3. Mathematical definition of reservoir various boundary conditions.

2.2. Solving the Coupled Equation. The coupled equations of dam-reservoirfoundation system are solved using the staggered displacement method in which the direct integration scheme is used to determine the displacement and hydrodynamic pressure at time increment $i+1$. The $\alpha$-method is utilized for discretization of both equations (implicit-implicit method). In this method, the velocity and displacement at time step $i+1$ can be written as 


$$
\begin{gathered}
\{\dot{U}\}_{i+1}=\{\dot{U}\}_{i+1}^{p}+\gamma \Delta t\{\ddot{U}\}_{i+1}, \\
\{\dot{U}\}_{i+1}^{p}=\{\dot{U}\}_{i}+(1-\gamma) \Delta t\{\ddot{U}\}_{i}, \\
\{U\}_{i+1}=\{U\}_{i+1}^{p}+\beta \Delta t^{2}\{\ddot{U}\}_{i+1}, \\
\{U\}_{i+1}^{p}=\{U\}_{i}+\Delta t\{\dot{U}\}_{i}+(0.5-\beta) \Delta t^{2}\{\ddot{U}\}_{i},
\end{gathered}
$$

where $\gamma$ and $\beta$ are the integration parameters. The similar equations can be written for determining $\{\dot{P}\}_{i+1}^{p},\{P\}_{i+1}$, and $\{P\}_{i+1}^{p}$. The terms with superscript $p$ represent displacement, velocity and pressure quantities at time step $i+1$ which are obtained using the pertinent quantities at time step $i$. The governing field equations at time $i+1$ can be written as

$$
\begin{gathered}
{[M]\{\ddot{U}\}_{i+1}+[C]\{\dot{U}\}_{i+1}+(1+\alpha)[K]\{U\}_{i+1}=} \\
=\left\{F_{1}\right\}_{i+1}+[Q]\{P\}_{i+1}+\alpha[K]\{U\}_{i}, \\
{[G]\{\ddot{P}\}_{i+1}+\left[C^{\prime}\right]\{\dot{P}\}_{i+1}+(1+\alpha)\left[K^{\prime}\right]\{P\}_{i+1}=} \\
=\left\{F_{2}\right\}_{i+1}-\rho[Q]^{T}\{\ddot{U}\}_{i+1}+\alpha\left[K^{\prime}\right]\{P\}_{i},
\end{gathered}
$$

where $\alpha$ is related to the numerical damping of the solver algorithm. The coupled field Eqs. (20) and (21) are solved using the staggered displacement solution scheme [41]. In this method, Eq. (20) is approximated as

$$
[M]\{\ddot{U}\}_{i+1}^{*}=\left\{F_{1}\right\}_{i+1}+[Q]\{P\}_{i+1}^{p}-(1+\alpha)[K]\{U\}_{i+1}^{p}+\alpha[K]\{U\}_{i} .
$$

Combining Eqs. (20) and (22) using Eqs. (18) and (19) gives

$$
\begin{gathered}
{[M]\{\ddot{U}\}_{i+1}=[M]\{\ddot{U}\}_{i+1}^{*}+\beta \Delta t^{2}[Q]\{\ddot{P}\}_{i+1}-\gamma \Delta t[c]\{\ddot{U}\}_{i+1}-} \\
-(1+\alpha) \beta \Delta t^{2}[K]\{\ddot{U}\}_{i+1} .
\end{gathered}
$$

The lumped mass results in a diagonal mass matrix. This property is utilized in modifying Eq. (23) such that

$$
[M]\{\ddot{U}\}_{i+1}=[M]\{\ddot{U}\}_{i+1}^{*}+\beta \Delta t^{2}[Q]\{\ddot{P}\}_{i+1} .
$$

Substituting Eq. (24) into Eq. (21), then

$$
\begin{gathered}
\left([C]+\rho \beta \Delta t^{2}[Q]^{T}[M]^{-1}[Q]\right)\{\ddot{P}\}_{i+1}+\left[C^{\prime}\right]\{\dot{P}\}_{i+1}+(1+\alpha)\left[K^{\prime}\right]\{P\}_{i+1}= \\
=\left\{F_{2}\right\}_{i+1}-\rho[Q]^{T}\{\ddot{U}\}_{i+1}^{*}+\alpha\left[K^{\prime}\right]\{P\}_{i} .
\end{gathered}
$$


In Eq. (25), the right hand side terms are known; thus, $\{P\}_{i+1}$ is obtained. In order to correct the approximation made in Eq. (24), $\{P\}_{i+1}$ is substituted in Eq. (13) to calculate $\{U\}_{i+1}$ and its derivatives. The procedure of the staggered displacement method is summarized by the following steps:

Step 1: Knowing the displacement, velocity and pressure at time $i,\{\ddot{U}\}_{i+1}^{*}$ is obtained from Eq. (22).

Step 2: $\{\ddot{U}\}_{i+1}^{*}$ is introduced in Eq. (25) to calculate $\{P\}_{i+1}$.

Step 3: $\{P\}_{i+1}$ is substituted into Eq. (20) to calculate $\{U\}_{i+1}$ and its derivatives.

3. Numerical Model and Finite Element Implementation. Karadj double curvature arch dam, located in Iran, is selected to obtain the effects of the orthotropic material on the nonlinear seismic response of the structure. The height of dam is $168 \mathrm{~m}$ and its crest length is $390 \mathrm{~m}$. Its thickness at the base and crest level are 32 and $7.85 \mathrm{~m}$, respectively. The normal water level for this dam is $1760 \mathrm{~m}$ in summer condition and corresponding reservoir capacity is $203 \mathrm{Mm}^{3}$. The vertical arches in this dam are consisting of quadratic curves where their equations are presented in Fig. 4a. In addition the radii of horizontal arches and corresponding central angle of arcs are shown in Fig. 4b. The general view and developed finite element model of dam-reservoir-foundation system are depicted in Fig. 5. The dam structure is modeled with 72 isoparametric twenty-node elements and its foundation medium surrounding the dam body is simulated using 980 elements. The depth of the foundation model is about twice of the dam height in the three global directions. The fluid is modeled using 1024 isoparametric eight-node fluid elements and is extended about twice of the dam height in the upstream direction.

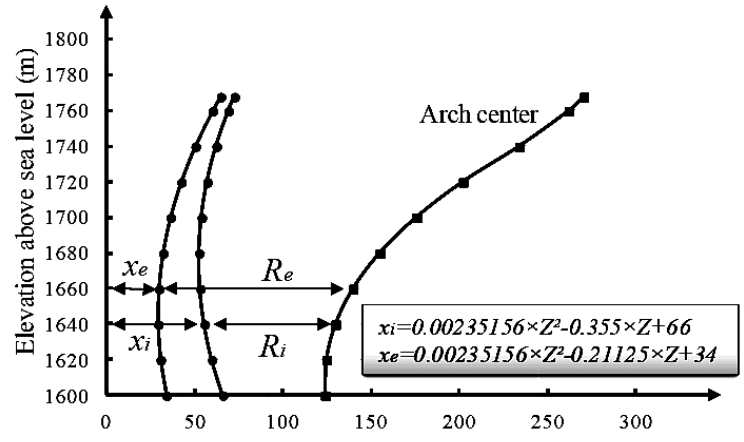

a

\begin{tabular}{cccc}
\hline $\begin{array}{c}\text { Level } \\
(\mathrm{m})\end{array}$ & $\begin{array}{c}\theta \\
(\text { degree })\end{array}$ & $R_{i}(\mathrm{~m})$ & $R_{e}(\mathrm{~m})$ \\
\hline 1768 & 109 & 197.970 & 205.8 \\
1760 & 109 & 192.900 & 201.900 \\
1740 & 110 & 171.896 & 183.771 \\
1720 & 115 & 144.997 & 159.747 \\
1700 & 117 & 121.784 & 139.409 \\
1680 & 115 & 102.438 & 122.938 \\
1660 & 110 & 86.774 & 110.149 \\
1640 & 90 & 74.338 & 100.588 \\
1620 & 76 & 64.853 & 93.978 \\
1600 & 52 & 58.000 & 90.000 \\
\hline
\end{tabular}

b

Fig. 4. Characteristics and equation of vertical arcs in central block (a) and geometric characteristics of the horizontal arcs (b).

The twenty-node isoparametric solid finite elements are implemented to model the structure, mathematically. The requirement for integration and generation of the mass, stiffness and damping matrices for this type of element is 27 Gaussian points in $3 \times 3 \times 3$ order within each element. Figure 6 a shows the ordering of the Gaussian points within the solid elements. Reservoir domain is modeled using eight-node isoparametric fluid elements with $2 \times 2 \times 2$ Gaussian integration points 


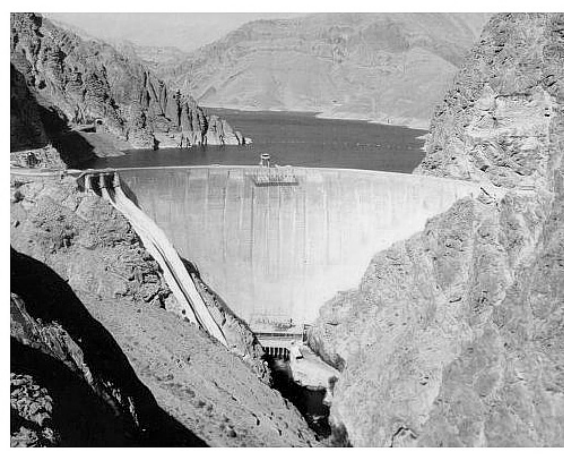

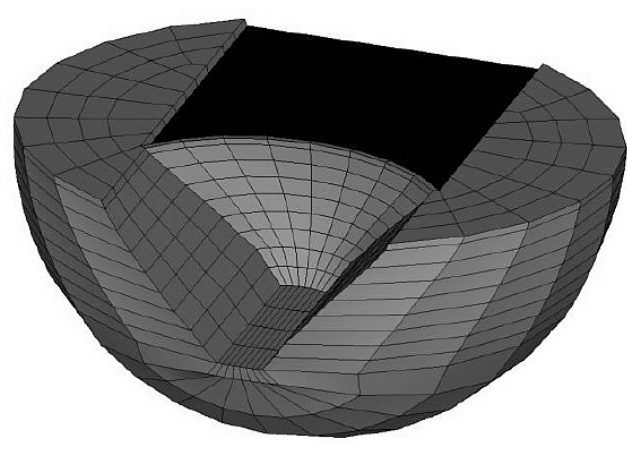

b

Fig. 5. General view of Karadj arch dam and its valley (a) and finite element model of the dam body, foundation, and reservoir (b).

(Fig. 6b). For the interface elements between the structure and the liquid, $3 \times 3$ Gaussian integration points are used (Fig. 6c) and for the other surface elements on the boundary of liquid, $2 \times 2$ Gaussian integration points are employed. For implementation of appropriate interaction in boundaries of reservoir domain, 64 surface elements are used on the reservoir-dam interface. Also 384 and 64 surface elements are used for modeling the reservoir-foundation interface and reservoir far-end boundary, respectively.

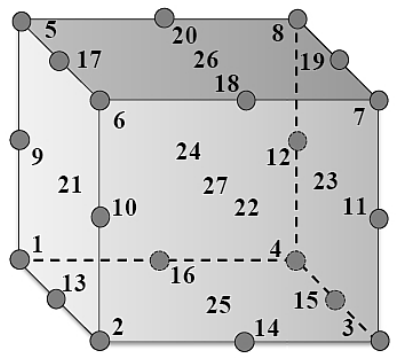

a

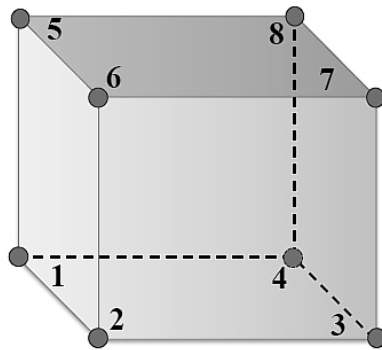

b

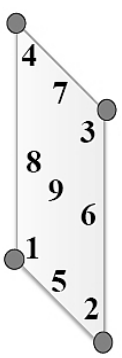

C

Fig. 6. Ordering of Gaussian points within twenty-node solid elements (a); eight-node fluid elements (b); four-node solid-fluid interface elements (c).

Material properties of mass concrete in isotropic and orthotropic conditions are extracted based on appropriate test as reported in Table 1. It is noteworthy that orthotropic material was considered in present study for take into account the effects of lift joints under static and seismic loads. In this paper the properties of orthotropic material is assumed to be same with isotropic material properties in two horizontal directions (horizontal dam section) and the new properties is defined for concrete in vertical direction (perpendicular to the lift surfaces).

For the foundation medium, the modulus of elasticity, Poisson's ratio, and the unit weight are taken as $16.3 \mathrm{GPa}, 0.15$, and $29.4 \mathrm{kN} / \mathrm{m}^{3}$, respectively. The velocity of wave propagation and the unit weight of water in the reservoir are assumed $1436 \mathrm{~m} / \mathrm{s}$ and $9.807 \mathrm{kN} / \mathrm{m}^{3}$, respectively. The wave reflection coefficient of the reservoir bottom and sides is given as 0.8 , conservatively. 
$\mathrm{T}$ a b 1 e 1

Isotropic and Orthotropic Properties of Mass Concrete

\begin{tabular}{||l|c|c|c|c||}
\hline \multirow{2}{*}{ Characteristic } & \multicolumn{2}{|c|}{ Isotropic material } & \multicolumn{2}{c||}{ Orthotropic material* } \\
\cline { 2 - 5 } & $\begin{array}{c}\text { Static } \\
\text { condition }\end{array}$ & $\begin{array}{c}\text { Dynamic } \\
\text { condition }\end{array}$ & $\begin{array}{c}\text { Static } \\
\text { condition }\end{array}$ & $\begin{array}{c}\text { Dynamic } \\
\text { condition }\end{array}$ \\
\hline Modulus of elasticity $(\mathrm{GPa})$ & 26.0 & 32.5 & 21.6 & 27.0 \\
\hline Poisson's ratio & 0.17 & 0.13 & 0.16 & 0.12 \\
\hline Unit weight $\left(\mathrm{kN} / \mathrm{m}^{3}\right)$ & 24.027 & 24.027 & 24.027 & 24.027 \\
\hline Tensile strength $(\mathrm{MPa})$ & 3.66 & 5.50 & 3.00 & 4.50 \\
\hline
\end{tabular}

* Orthotropic properties presented here are in vertical direction. Properties for other directions are same as isotropic material.

The stiffness proportional damping is used in the conducted analyses in which the damping ratio for the fundamental mode is taken to be $10 \%$. Applied loads on the system are the self weight, the hydrostatic pressure and the seismic load. The values of the integration parameters in the $\alpha$-method are taken as $\alpha=-0.2$, $\beta=0.36$, and $\gamma=0.7$. The quasi-linear damping mechanism is used for the structure in the dynamic analysis in which the stiffness proportional damping is updated during the element cracking within the dam body.
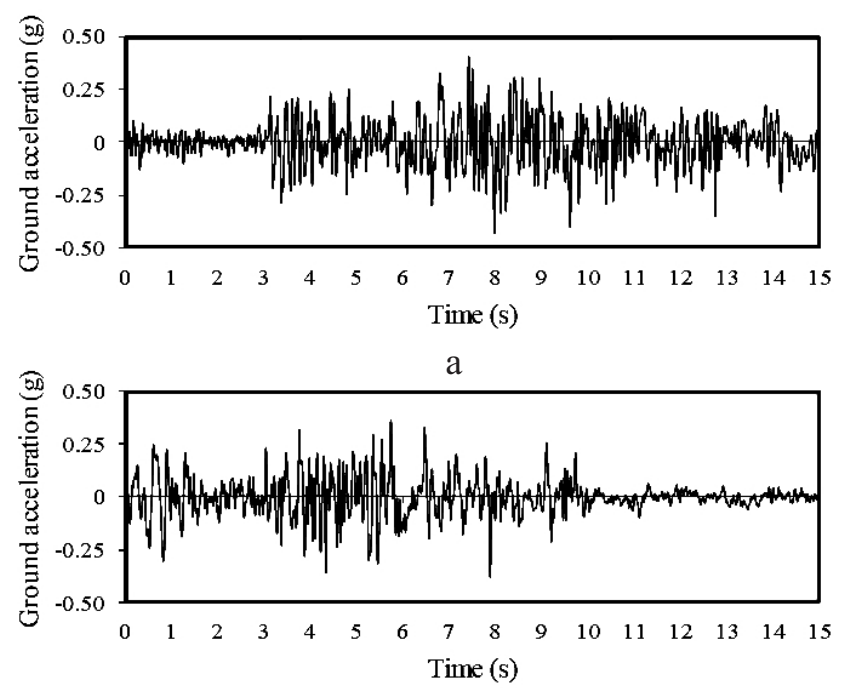

b

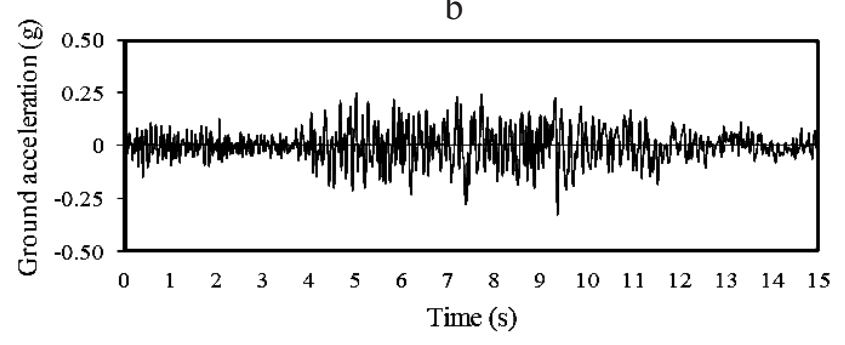

$\mathrm{c}$

Fig. 7. Components of the Manjil earthquake on 20 June1990: (a) US/DS component; (b) crossstream component; (c) vertical component. 
Figure 7 shows three components of the ground motion recorded at the Ab-Bar station during Manjil earthquake at 20 June 1990, which was chosen for the analyses. It's noteworthy that record has been obtained based on probabilistic seismic hazard analysis of dam site and normalized/filtered for the Karadj dam site. The horizontal and vertical PGAs at maximum credible level (MCL) are 0.43 and $0.33 \mathrm{~g}$ at the dam site, respectively.

4. Results. This section provides the results of linear and nonlinear analysis of dam-reservoir-foundation system in seismic condition. Figure 8 shows the comparison of displacement time-history at mid-point of the crest in the stream direction for isotropic and orthotropic materials resulted from linear analysis. As can be seen, both models experience crest displacement about $39 \mathrm{~mm}$ in the DS direction due to self-weight and hydrostatic pressure. There is great consistency between the two models under seismic loads. The maximum crest displacement in the downstream direction for isotropic material is $111.8 \mathrm{~mm}$ while this value for the model with orthotropic material reaches $113.5 \mathrm{~mm}$. The same consistency between the provided two models can be found in the vertical and cross-stream directions so that the maximum crest displacements in vertical and cross stream directions for the case with isotropic material are 34.3 and $46 \mathrm{~mm}$, respectively. These values for the case with orthotropic material reach to 35.1 and $45.4 \mathrm{~mm}$.

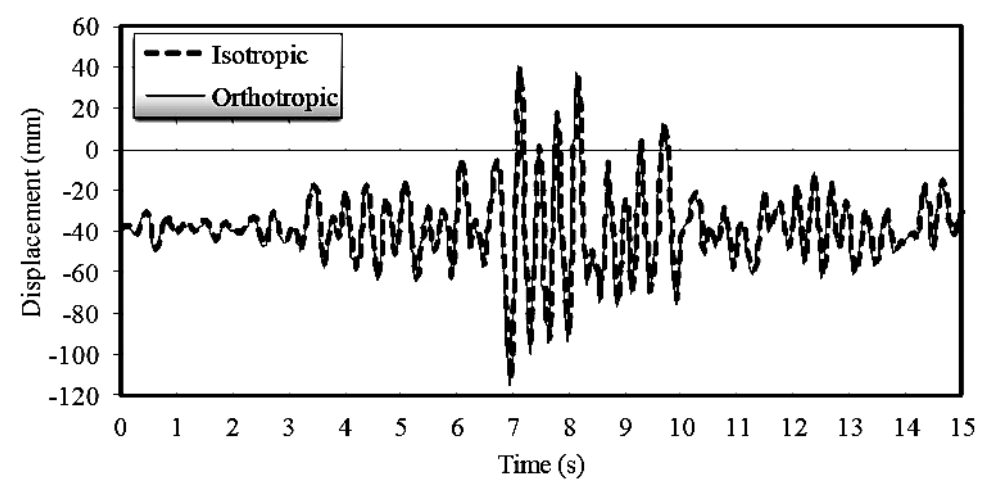

Fig. 8. Time-history of crest displacement in the stream direction using linear analysis for isotropic and orthotropic materials.

For the case with isotropic material, both maximum tensile arch and cantilever stresses occur at time $7.050 \mathrm{~s}$. Figure 9 shows the contours of arch and cantilever stresses at the time of maximum stresses occurrence. As can be seen, high arch stresses occur on the US face in vicinity of the crest and also on the DS face near the abutments and at the bottom of the dam body. In addition, due to cantilever action of the blocks, high cantilever stresses are observed on the US face in vicinity of the crest and also at upper parts of the DS face near the crest and abutments.

Utilizing orthotropic material in the model leads to generation of maximum tensile arch and cantilever stresses at different times. Based on the results, the maximum tensile arch stress occurs at time $7.050 \mathrm{~s}$, while the maximum tensile cantilever stress occurs at time $7.475 \mathrm{~s}$. Figure 10 shows contours of arch and cantilever stresses at the time of maximum stresses occurrence. Looking at the figures, the location of high tensile arch stresses on the US and DS faces are very 


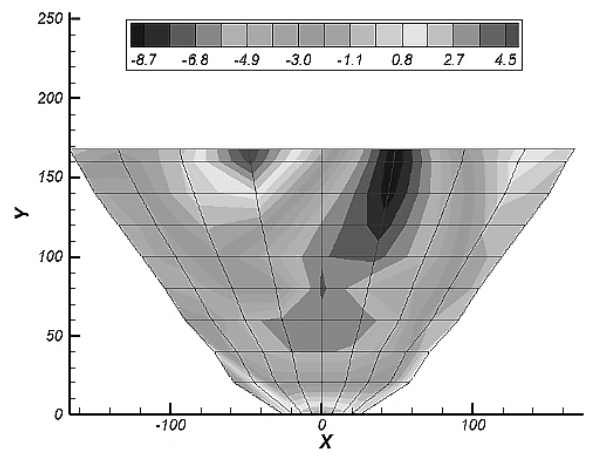

a

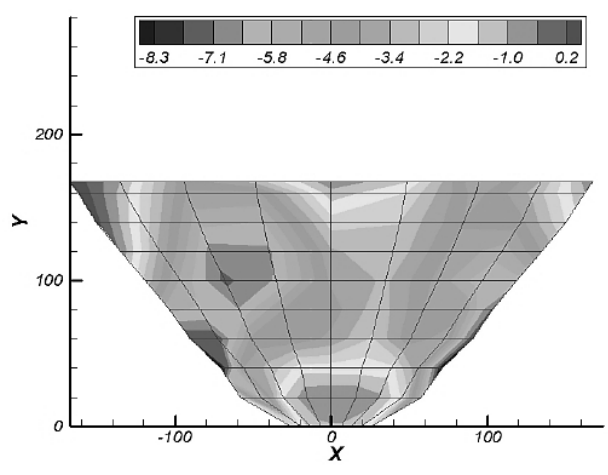

b

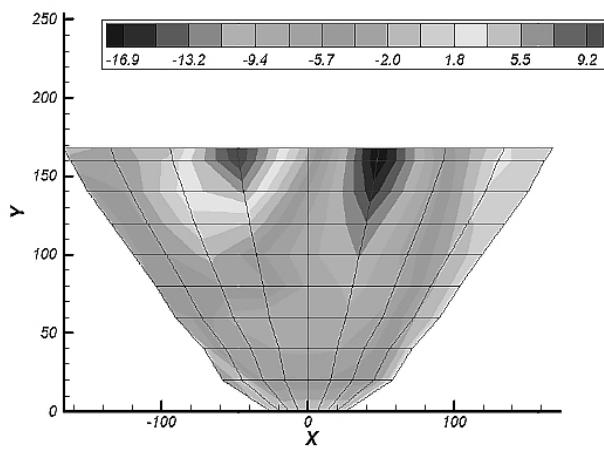

c

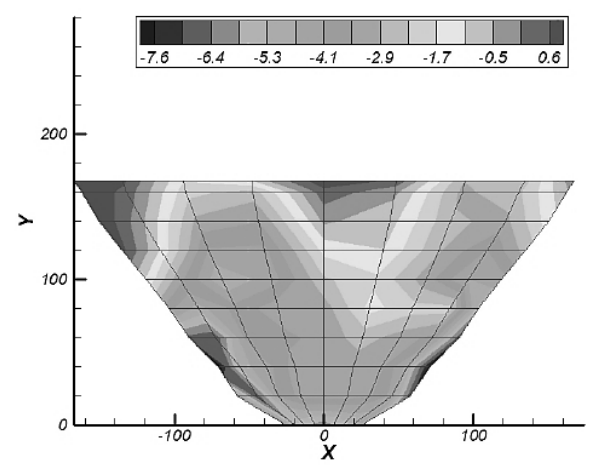

d

Fig. 9. Arch and cantilever stress contours at the time of maximum stresses based on linear analysis and isotropic material using mass-less foundation: (a) arch stress in US; (b) arch stress in DS; (c) cantilever stress in US; (d) cantilever stress in DS.

similar in the cases with isotropic and orthotropic materials. On the other hand, location of high tensile cantilever stresses resulted from the two provided modes are different, especially on the DS face.

Figure 11 represents time-history of the crest displacement in the stream direction when tensile cracking is permitted within the dam body. As in linear analyses, the two nonlinear analyses are conducted so that at the first analysis, the initial material defined for the intact mass concrete is isotropic and for the second one, the intact material is orthotropic so that the initial elastic modulus and tensile strength in vertical direction is different from the two other directions. Clearly, after cracking initiation at each Gaussian point, the behavior at the cracked point is anisotropic as defined in the proposed damage mechanics model.

As the previous analyses with linear models, there is good consistency between the two models while using nonlinear models lead to higher displacements. The maximum displacement for isotropic-based material is $117.4 \mathrm{~mm}$ in the downstream direction while due to utilizing orthotropic material the crest experiences $128.7 \mathrm{~mm}$ movement in the downstream direction. In addition based on the isotropic material used model, the dam has displacements about 48.3 and $36.02 \mathrm{~mm}$ in the cross-stream and vertical directions, respectively. The values of corresponding displacements using orthotropic material are 50.4 and $40.21 \mathrm{~mm}$. 

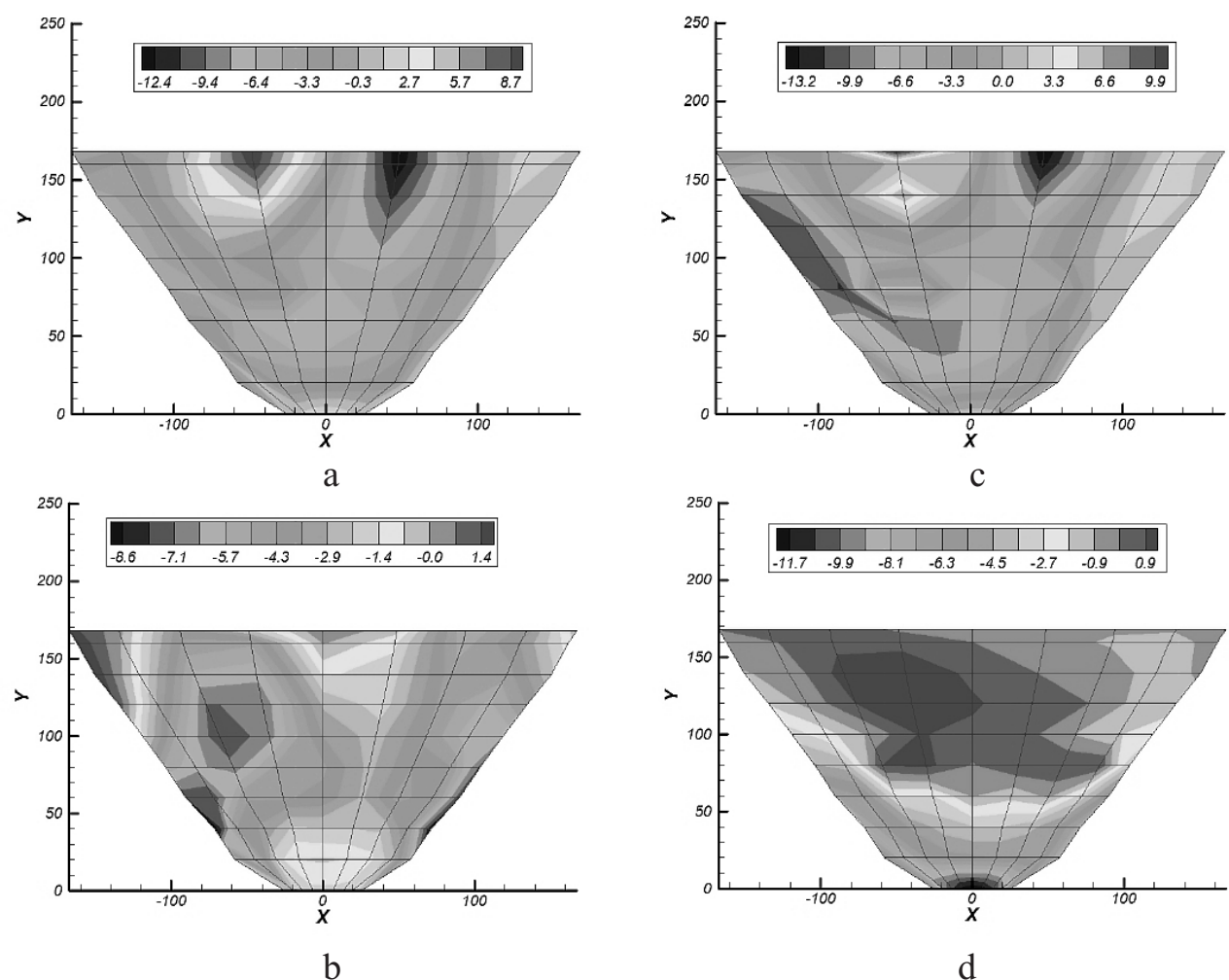

Fig. 10. Arch and cantilever stress contours at the time of maximum stresses based on linear analysis and orthotropic material using mass-less foundation: (a) arch stress in US; (b) arch stress in DS; (c) cantilever stress in US; (d) cantilever stress in DS.

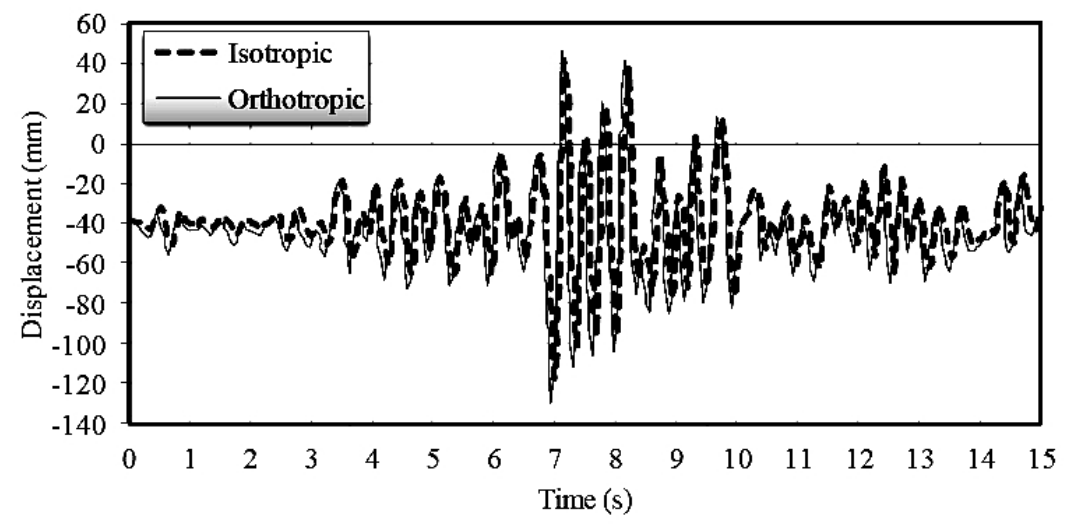

Fig. 11. Time-history of crest displacement in stream direction using nonlinear analysis for isotropic and orthotropic materials.

Figure 12 shows crack profiles within the dam body at the end of the nonlinear analysis. As can be seen, in the model using isotropic-based material, there is just one cracked element under seismic loads while using orthotropicbased material leads to more severe damage within the dam body. The cracked areas are concentrated in bottom of the dam and also upper parts of the body near the crest. 


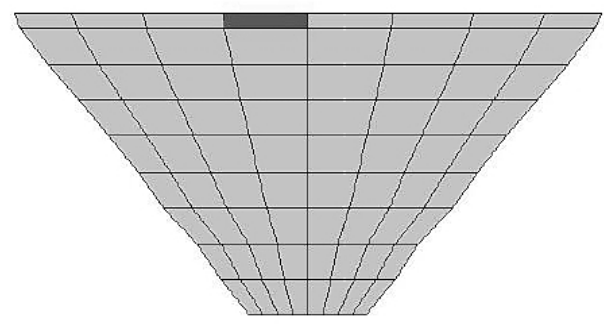

a

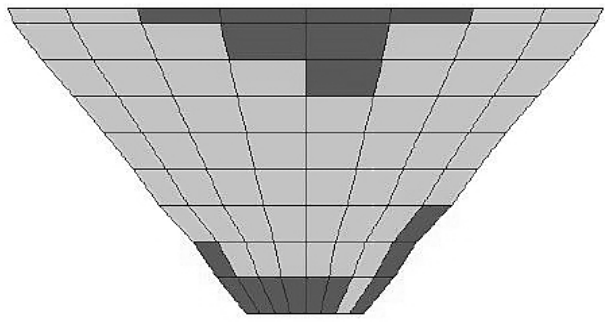

b

Fig. 12. Crack profile under nonlinear seismic analysis using mass-less foundation in isotropic- (a) and orthotropic-based (b) material.

6. Discussion. In the previous section the linear and nonlinear response of arch dam-reservoir-foundation system was studied using isotropic-based and orthotropic-based material. Foundation medium was assumed to be mass-less and just its stiffness matrix was considered in overall coupled equations. Table 2 summarizes the values of crest displacement in three orthogonal directions. As can be seen, almost in all cases using orthotropic-based material leads to higher displacement. Also damage analysis of the system leads to more displacement due to cracking of elements and softening of the dam body.

$\mathrm{T}$ a b 1 e 2

Maximum Displacement Values (mm) in Crest Points Using Mass-Less Foundation

\begin{tabular}{|c|c|c|c|c|c|c|c||}
\hline \multirow{2}{*}{ Model } & \multirow{2}{*}{ Position } & \multicolumn{3}{|c|}{ Isotropic-based material } & \multicolumn{3}{|c|}{ Orthotropic-based material } \\
\cline { 3 - 8 } & & Stream & Cross-stream & Vertical & Stream & Cross-stream & Vertical \\
\hline \multirow{2}{*}{ Linear } & Mid-point & 111.8 & 46.0 & 34.3 & 113.5 & 45.4 & 35.1 \\
& Left-quarter & 70.1 & 44.9 & 13.7 & 78.1 & 46.6 & 15.3 \\
& Right-quarter & 69.1 & 31.9 & 15.2 & 66.8 & 36.6 & 16.0 \\
\hline \multirow{2}{*}{ Nonlinear } & Mid-point & 117.4 & 48.3 & 36.0 & 128.7 & 50.4 & 40.2 \\
& Left-quarter & 73.6 & 47.1 & 14.4 & 80.0 & 49.5 & 17.6 \\
& Right-quarter & 72.5 & 33.5 & 15.9 & 80.4 & 39.1 & 19.2 \\
\hline
\end{tabular}

Figure 13 shows the contours of arch and cantilever tensile stresses at the time of maximum stresses for linear analysis of the dam body on rigid foundation for isotropic-based materials. Maximum tensile arch stresses are at $t=8.135 \mathrm{~s}$ while the maximum of tensile cantilever stresses occurs at $t=7.515 \mathrm{~s}$. The location of high arch stresses are the same with those obtained from mass-less foundation while the area with high cantilever stresses are relocated from upper parts of the dam in mass-less model to the interface of the dam-foundation and also middle part of the dam body in the rigid foundation model. The values of arch stresses have increased in the case with rigid foundation while the values of cantilever stresses have reduced. Figure 14 represents the same plots for orthotropic-based materials in linear analysis of the system on the rigid foundation. Using rigid foundation decreases both arch and cantilever stresses for orthotropic materials. 

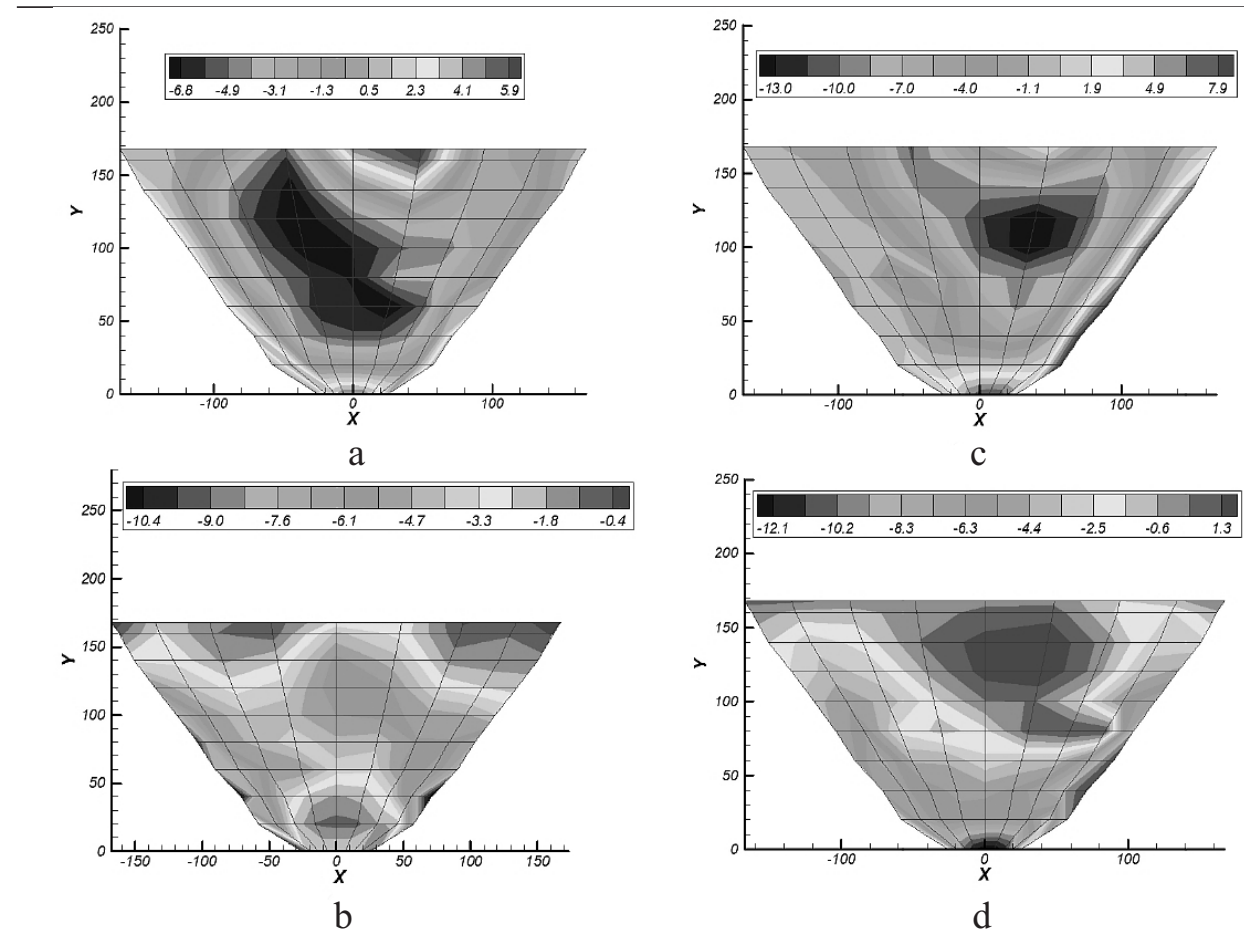

Fig. 13. Arch and cantilever stress contours at the time of maximum stresses based on linear analysis and isotropic material using rigid foundation: (a) arch stress in US; (b) arch stress in DS; (c) cantilever stress in US; (d) cantilever stress in DS.
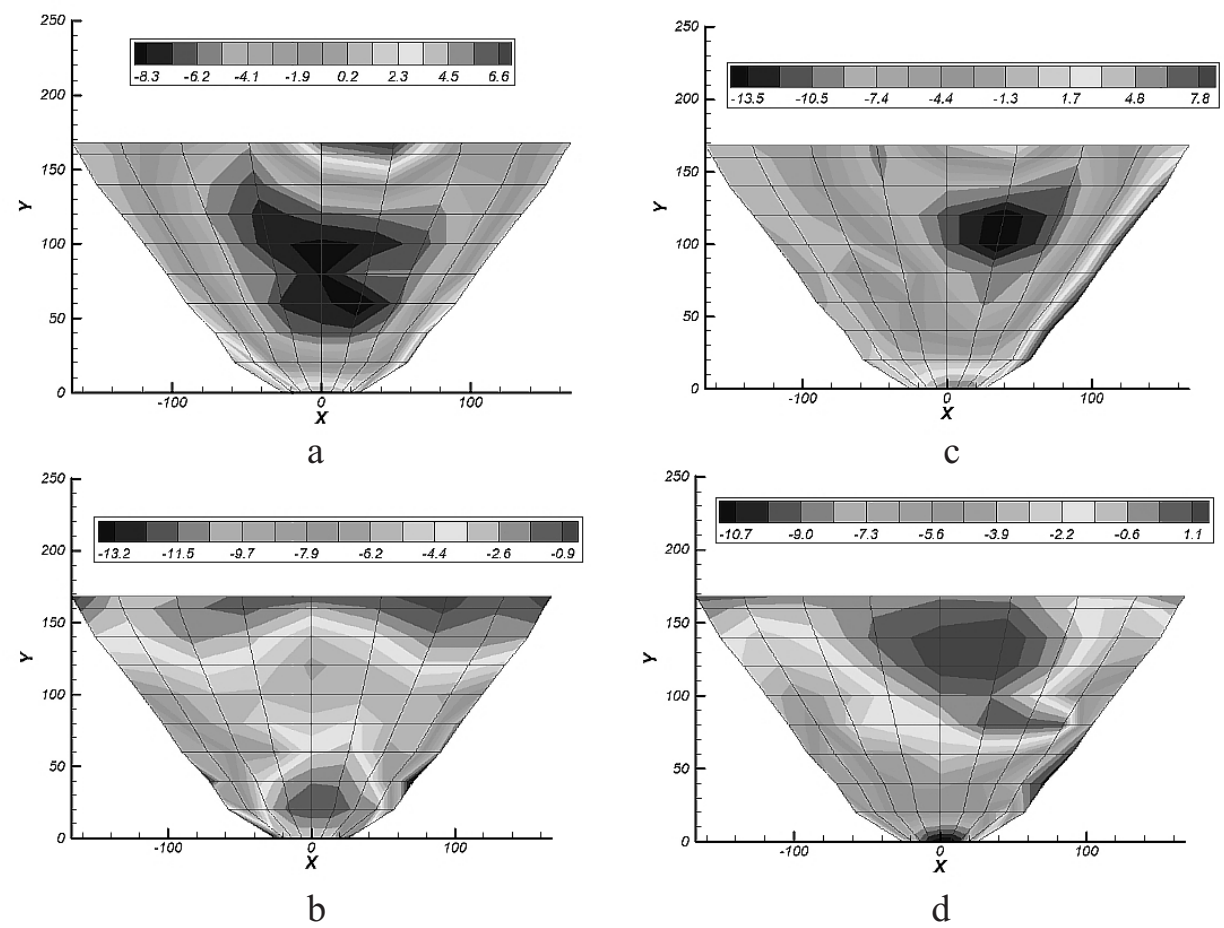

Fig. 14. Arch and cantilever stress contours at the time of maximum stresses based on linear analysis and orthotropic material using rigid foundation: (a) arch stress in US; (b) arch stress in DS; (c) cantilever stress in US; (d) cantilever stress in DS. 
Table 3 summarizes the values of crest displacement in three directions using the system with rigid foundation. Like as mass-less foundation model using orthotropic-based material leads to higher displacement for most cases. In addition, comparing the two models, it can be found that we have lower values of displacements for the model with rigid foundation, which is logical and expected.

$\mathrm{T}$ a b 1 e 3

Maximum Displacement Values (mm) in Crest Points Using Rigid Foundation

\begin{tabular}{||c|c|c|c|c|c|c|c||}
\hline \multirow{2}{*}{ Model } & \multirow{2}{*}{ Position } & \multicolumn{3}{|c|}{ Isotropic-based material } & \multicolumn{3}{c||}{ Orthotropic-based material } \\
\cline { 3 - 8 } & & Stream & Cross-stream & Vertical & Stream & Cross-stream & Vertical \\
\hline \multirow{2}{*}{ Linear } & Mid-point & 101.0 & 30.6 & 36.4 & 103.0 & 34.0 & 37.2 \\
& Left-quarter & 49.6 & 22.8 & 8.9 & 51.1 & 32.4 & 9.8 \\
& Right-quarter & 56.8 & 22.2 & 10.1 & 62.5 & 24.2 & 11.6 \\
\hline \multirow{2}{*}{ Nonlinear } & Mid-point & 107.3 & 33.8 & 39.5 & 117.0 & 37.9 & 42.8 \\
& Left-quarter & 61.2 & 23.6 & 10.8 & 55.9 & 29.0 & 11.8 \\
& Right-quarter & 61.2 & 23.7 & 13.9 & 65.8 & 25.5 & 15.2 \\
\hline
\end{tabular}

Figure 15 shows crack profile in the dam body at the end of the nonlinear analysis when the system is on the rigid foundation. Like the previous model, orthotropic-based material leads to more damage. For the isotropic-based material the number of cracked elements is same in mass-less and rigid foundations (one cracked elements) while its location differs. For the orthotropic-based material the crack profiles are completely different, in a way that the cracked elements are distributed in lower and upper parts of the body.

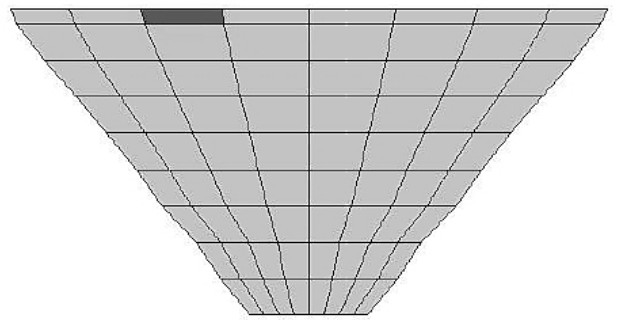

a

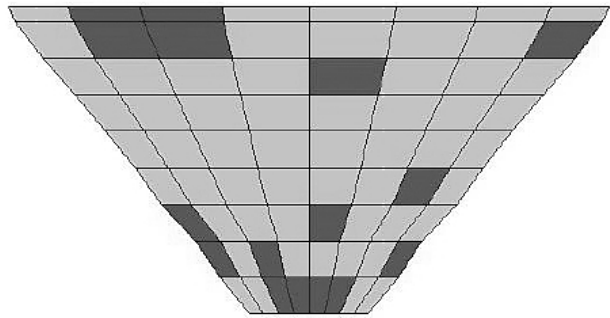

b

Fig. 15. Crack profile under nonlinear seismic analysis using mass-less foundation in isotropic- (a) and orthotropic-based (b) material.

One of the main shortcomings of the conducted analyses is neglecting the effect of vertical joints due to scope limit of the study. Obviously, vertical contraction joints can affect the seismic response of the body significantly. However, the main object of the current study is considering the lift joint effects on the seismic response. Taking into account the vertical joint effects is in future work of the authors. 
Conclusions. In the present paper, an anisotropic damage mechanics approach was introduced and its application for seismic assessment of concrete arch dam-reservoir-foundation system was investigated. Due to main object of the study and considering that the effects of contraction joints have been investigated by many researchers simulation of contraction joints was neglected in the present case and only lift joints were taken into account. Two different characteristics were assumed for mass concrete in which in the first model, the dam body was modeled using isotropic material and in the second one orthotropic material was used in a direction perpendicular to the lift surfaces in order to considering weak horizontal planes. Reservoir was modeled by Eulerian fluid elements and foundation medium assumed to be both rigid and mass-less. The dynamic equilibrium equation of the coupled system was solved using the staggered displacement method.

Results show that generally, using orthotropic-based material lead to higher values of displacements in benchmark points in comparison with the model with isotropic-based material in both linear and nonlinear analyses; however their differences are significant for nonlinear case (using anisotropic damage mechanics). In addition, using mass-less foundation leads to higher displacement than rigid one. Due to arrangement of material properties, in both isotropic- and orthotropic-based materials and also mass-less and rigid foundations, the pattern of arch stresses at the time of maximum arch stress are close to each other and concentrated in vicinity of the crest on the upstream face and near the abutments on the downstream face. Because of different properties of orthotropic-based material in vertical direction, the pattern of cantilever stresses has some differences especially on the downstream face. Mass-less foundation leads to relocation of the area with high cantilever stresses from upper parts of the dam to the dam-foundation interface and also middle part of the body. Moreover, using orthotropic-based materials in conjunction with anisotropic damage mechanics approach generates more damages in the dam body than to isotropic-based materials for both mass-less and rigid foundations; however the crack profile changes by foundation condition.

\section{Резюме}

На відміну від моделювання усадкових швів, при чисельному аналізі бетонних арочних гребель робота і вплив будівельних швів зазвичай не враховуються. Досліджується сейсмічна нелінійна реакція системи (бетонна) арочна гребля-резервуар-основа з урахуванням дії будівельних швів на основі ортотропного матеріалу. Представлений анізотропний підхід до механіки руйнування змінено для урахування слабких горизонтальних площин між шарами бетону в процесі будівництва. Ця модель допускає урахування характеристики попереднього розм'якшення, критерію виникнення розм'якшення і характеристики анізотропного розтріскування. За допомогою методу східчастих переміщень, припускаючи, що скельову основу складають невагомі жорсткі тіла, розв'язано систему зв'язаних рівнянь руху в системі гребля-резервуар. Рух грунту за трикомпонентною технологією збуджує дану систему на максимально імовірному рівні. Установлено, що використання ортотропного матеріалу збільшує зміщення гребеня греблі i, як наслідок, пошкодження тіла греблі в більшій мірі порівняно з використанням розповсюдженого ізотропного матеріалу. 
1. J. R. Hess, "RCC lift-joint strength," Concrete Int., 24, No. 1, 50-56 (2002).

2. H. Arabshahi and V. Lotfi, "Nonlinear dynamic analysis of arch dams with joint sliding mechanism," Eng. Comput., 26, No. 5, 464-482 (2009).

3. L. Fronteddu, P. Leger, and R. Tinawi, "Static and dynamic behavior of concrete lift joint interfaces," J. Struct. Eng., 124, No. 12, 1418-1430 (1998).

4. E. Puntel, G. Bolzon, and V. E. Saouma, "An experimental and numerical investigation of concrete dam joints," in: Proc. 11th Int. Conf. on Fracture (ICF XI), Turin, Italy (2005), p. 396.

5. S. Mojtahedi and G. Fenves, Effects of Contraction Joint Opening on Pacoima Dam in 1994 Northridge Earthquake, Report CSMIP/00-05, University of California, Berkeley, USA (2000).

6. S. Malla and M. Wieland, "Analysis of an arch-gravity dam with a horizontal crack," Comput. Struct., 72, 267-278 (1999).

7. M. Wieland and S. Malla, "Earthquake safety of an arch-gravity dam with a horizontal crack in the upper portion of the dam," in: Proc. 12th World Conf. on Earthquake Engineering, Auckland, New Zealand (2000).

8. N. R. Hansen and H. L. Schreyer, "A thermodynamically consistent framework for theories of elasto-plasticity coupled with damage," Int. J. Solids Struct., 31, No. 3, 359-389 (1994).

9. I. Doghri and L. Tinel, "Micromechanical modeling and computation of elasto-plastic materials reinforced with distributed orientation fibers," Int. J. Plasticity, 21, No. 10, 1919-1940 (2005).

10. A. Menzel, M. Ekh, K. Runesson, and P. Steinmann, "A framework for multiplicative elastoplasticity with kinematic hardening coupled to anisotropic damage," Int. J. Plasticity, 21, 397-434 (2005).

11. G. Z. Voyiadjis, Z. N. Taqieddin, and P. I. Kattan, "Theoretical formulation of a coupled elastic-plastic anisotropic damage model for concrete using the strain energy equivalence concept," Int. J. Damage Mech., 18, No. 7, 603-638 (2009).

12. J. Lee and G. L. Fenves, "A plastic-damage model for cyclic loading of concrete structures," J. Eng. Mech., 124, No. 8, 892-900 (1998).

13. L. Jason, G. Pijaudier-Cabot, A. Huerta, et al., "An elastic plastic damage formulation for the behavior of concrete," in: V. Li, C. K. Y. Leung, K. J. William, and S. L. Billington,, (Eds.), Fracture Mechanics of Concrete Structures (2004), p. 549-556.

14. N. Bonora, D. Gentile, A. Pirondi, and G. Newaz, "Ductile damage evolution under triaxial state of stress: theory and experiments," Int. J. Plasticity, 21, 981-1007 (2005).

15. L. Jason, A. Huerta, G. Pijaudier-Cabot, and S. Ghavamian, “An elastic plastic damage formulation for concrete: application to elementary tests and comparison with an isotropic damage model," Comput. Meth. Appl. Mech. Eng., 195, 7077-7092 (2006).

16. A. Pirondi, N. Bonora, D. Steglich, et al., "Simulation of failure under cyclic plastic loading by damage models," Int. J. Plasticity, 22, 2146-2170 (2006). 
17. J. U. Wu, J. Li, and R. Faria, "An energy release rate-based plastic-damage model for concrete," Int. J. Solids Struct., 43, 583-612 (2006).

18. D. J. Celentano and J. L. Chaboche, "Experimental and numerical characterization of damage evolution in steels," Int. J. Plasticity, 23, 17391762 (2007).

19. J. L. Chaboche, "Development of continuum damage mechanic for elastic solids sustaining anisotroic and unilateral damage," Int. J. Damage Mech., 2, 311-329 (1993).

20. G. Z. Voyiadjis and T. M. Abu-Lebdeh, "Plasticity model for concrete using the bounding surface concept," Int. J. Plasticity, 10, 1-21 (1994).

21. S. Govindjee, G. J. Kay, and J. C. Simo, "Anisotropic modelling and numerical simulation of brittle damage in concrete," Int. J. Num. Meth. Eng., 38, 3611-3633 (1995).

22. D. Halm and A., Dragon, "A model of anisotropic damage by mesocrack growth: unilateral effect," Int. J. Damage Mech., 5, 384-402 (1996).

23. I. Carol, E. Rizzi, and K. J. William, "On the formulation of anisotropic elastic degradation. II: Generalized pseudo-Rankine model for tensile damage," Int. J. Solids Struct., 38, 519-546 (2001).

24. E. Hansen, K. William, and I. Carol, "A two-surface anisotropic damage/ plasticity model for plain concrete," in: R. de Borst, J. Mazars, G. PijaudierCabot, and J. G. M. van Mier (Eds.), Fracture Mechanics of Concrete Structures, Lisse, Balkema (2001), pp. 549-556.

25. F. Gatuingt and G. Pijaudier-Cabot, "Coupled damage and plasticity modeling in transient dynamic analysis of concrete," Int. J. Num. Anal. Meth. Geomech., 26, 1-24 (2002).

26. M. Brunig, "An anisotropic ductile damage model based on irreversible thermodynamics," Int. J. Plasticity, 19, 1679-1713 (2003).

27. U. Cicekli, G. Z. Voyiadjis, and R. K. Abu Al-Rub, "A plasticity and anisotropic damage model for plain concrete," Int. J. Plasticity, 23, 18741900 (2007).

28. Y. Hammi and M. F. Horstemeyer, "A physically motivated anisotropic tensorial representation of damage with separate functions for void nucleation, growth, and coalescence," Int. J. Plasticity, 23, 1641-1678 (2007).

29. F. Ghrib and R. Tinawi, "Nonlinear behavior of concrete dams using damage mechanics," J. Eng. Mech., 121, No. 4, 513-526 (1995).

30. F. Ghrib and R. Tinawi, "An application of damage mechanics for seismic analysis of concrete gravity dams," Earthquake Eng. Struct. Dynamics, 24, 157-173 (1995).

31. H. Mirzabozorg, M. Ghaemian, and M. R. Kianoush, "Damage mechanics approach in seismic analysis of concrete gravity dams including dam-reservoir interaction," Eur. Earthquake Eng., XVIII, No. 3, 17-24 (2004).

32. R. M. Gunn, "Non-linear design and safety analysis of arch dams using damage mechanics. Pt. 1: Formulation," Hydropowers \& Dams, 2, 67-74 (2001). 
33. R. M. Gunn, "Non-linear design and safety analysis of arch dams using damage mechanics. Pt. 2: Applications," Hydropowers \& Dams, 3, 74-80 (2001).

34. H. Horii and S. C. Chen, "Computational fracture analysis of concrete gravity dams by crack-embedded elements-toward an engineering evaluation of seismic safety," Eng. Fract. Mech., 70, 1029-1045 (2003).

35. J. Oliver, A. Huespe, M. D. G. Pulido, and S. Blanco, "Computational modeling of cracking of concrete in strong discontinuity settings," Comput. Struct., 1, No. 1, 61-76 (2004).

36. O. A. Pekau and C. Yuzhu, "Failure analysis of fractured dams during Earthquake by DEM," Eng. Struct., 26, 1483-1502 (2004).

37. Y. Calayir and M. Karaton, "A continuum damage concrete model for earthquake analysis of concrete gravity dam-reservoir systems," Soil Dyn. Earthquake Eng., 25, 857-869 (2005).

38. M. Ardakanian, M. Ghaemian, and H. Mirzabozorg, "Nonlinear behavior of mass concrete in three-dimensional problems using damage mechanics approach," Eur. Earthquake Eng., 2, 65-89 (2006).

39. S. Oliveira and R. Faria, "Numerical simulation of collapse scenarios in reduced scale tests of arch dams," Eng. Struct., 28, 1430-1439 (2006).

40. H. Mirzabozorg, 3D Nonlinear Seismic Analysis of Concrete Dams Considering Dam-Reservoir Interaction Effects, Ph.D. Thesis, Sharif University of Technology, Tehran, Iran (2003).

41 H. Mirzabozorg, A. R. Khaloo, and M. Ghaemian, "Staggered solution scheme for three dimensional analysis of dam reservoir interaction," Dam Eng., 14, No. 3, 147-179 (2003). 